\title{
PLANTER PABRIK GULA PEKALONGAN MENGGUGAT UPAH
}

\author{
MASA CULTUURSTELSEL
}

\begin{abstract}
Two main things leading to the selection of Java to be the area of investment by Dutch colonial were the presence of the labors and the cheap land or in another words it was the lower production cost. The prerequisites of the condition establishment were put in the period of Cultuurstelsel i.e. when the political and economic obstacles determined their form in the coordinating institution of the natives' power use as mediation for the deployment. For the natives, the presence of the financial capital began to be sensed when the plantation industry was established. The industrial work pattern emerged, which was a combination of agricultural employment of export plants with manufacturing employment. The concrete form was sugar factories. The issues mainly arose in how the manner of the Gubernemen conditioned various social strata, from the elite top to small farmers to get involved to support the planting projects in ondernemings and the process of turning the sugarcanes into sugar.
\end{abstract}

Keywords: Planter, Sugar Factories, Cultuurstelsel, Wage

\begin{abstract}
Abstrak
Dua hal utama yang menyebabkan dipilihnya Jawa menjadi lahan penanaman modal oleh negara kolonial Hindia Belanda adalah terdapatnya tenaga kerja dan tanah yang murah, atau dengan kata lain biaya produksi yang rendah. Prasyarat pembentukan kondisi tersebut diletakkan dalam kurun Cultuurstelsel. Yaitu, ketika berbagai kendala politik dan ekonomi menentukan bentuknya dalam wadah penggunaan kekuasaan pribumi sebagai mediasi bagi pengerahannya. Bagi masyarakat pribumi hadirnya modal mulai dirasakan ketika didirikan industri perkebunan. Muncul pola kerja industri yang merupakan gabungan kerja agrikultur penanaman tanaman ekspor, dengan kerja manufaktur. Wujud kongkritnya adalah pabrik gula. persoalan timbul terutama pada cara bagaimana gubernemen mengkondisikan berbagai lapisan sosial dari elit teratas hingga kaum petani kecil diserap untuk mendukung berjalannya proyek-proyek penanaman di onderneming-onderneming dan proses pengolahan tebu menjadi gula.
\end{abstract}


Kata kunci: Planter, Pabrik Gula, Upah, Cultuurstelsel, Upah Pendahuluan

Sebelum tahun 1800 kerja dilakukan semata-mata untuk hasil yang dikonsumsi sendiri oleh masyarakat petani Jawa. Kerja-kerja yang umumnya dilakukan dalam jalinan ikatan-ikatan perhambaan untuk kepentingan komunitasnya sendiri. Jika ada kelebihan maka kelebihan tersebut terserap sebagai upeti oleh lapisan elit setempat.

Kerja tak berupah muncul pada masyarakat ini dalam bentuk pertama kerja wajib untuk lapisan elit setempat yang dikenal dengan sebutan pancen (pantjendienst) atau kriegandienst; kedua kerja karena terlibat hutang yang mesti dilunasi dengan kerja mengabdi pada si pemberi hutang, dan ketiga adalah bentuk perbudakan, yang banyak diserap oleh VOC dengan menggunakan institusi-institusi yang ada dalam pengerahan dan penyerahan tenaga kerja oleh para kepala "feodal". ${ }^{1}$ Kerja-kerja tersebut dilakukan tanpa adanya lalu lintas uang sebagai upah. ${ }^{2}$

Upah mulai dikenal awal abad ke-19, ketika Raffles memperkenalkan uang sebagai alat tukar kepada masyarakat pribumi. Apa yang dilakukan Raffles dengan memasyarakatkan

1 Suri Suroto, Gerakan Buruh dan Permasalahannya (Prisma, No. $11,1985)$, hal 26

2 Namun terdapat pula pengecualiannya di ommelanden Batavia, dalam pengoprasian pengilingan-pengilingan gula, para pengelola memberikan upah-upah tunai. Meskipun jenis uang yang digunakan hanya berlaku untuk ditukarkan pada warung-warung Cina setempat yang menyediakan kebutuhan pokok (beras) dan candu. (Gordon R. Knight, From Plantation to Padi-field, hal 187) Akan tetapi gejala ini tidak terlalu umum, sebab sebagian besar populasi pribumi belum melihat kegunaan atau fungsi praktis dari uang. Di beberapa tempat, selama kurun VOC, bahkan ditemui uang dipakai sebagai perhiasan semata. [J. van Zwijndregt dan B.H. Schoonenberg, Peladjaran Ekonomi Cetakan ke2 (Jakarta: J.B. Wolters), hal 16] 
uang pada petani Jawa, adalah dalam rangka menjaring masyarakat Jawa untuk memasuki lingkungan pasar. Sebagaimana diketahui akibat Revolusi Industri di Inggris, maka terjadi ekspansi pemasaran tekstil yang intensif ke seluruh dunia. Uang menjadi diperlakukan sebagai alat tukar. Karena itu seluruh pelosok yang diekspansi oleh perdagangan Inggris ini harus disiapkan untuk menerima barang-barang produksinya, sebagai negeri yang pertama kali melakukan revolusi produksi ini.

Meskipun politik dagang Inggris menjadi tidak efektif setelah Inggris meninggalkan Jawa dalam tahun 1816, namun persebaran uang berlanjut semakin luas. Seperti, dalam tahun 1820-an hampir setiap pekerjaan dapat mendatangkan uang, misalnya di Pekalongan, umumnya pekerjaan tukang pacul bertarif 10 duit, tukang bajak sawah 12 duit sehari. Sedang pekerjaan dalam penggilingan tebu menjajikan antara 12 hingga 14 gulden per bulan bagi seorang penebang tebu, dan 5 gulden bagi juru masak tebu (untuk tiap pemasakan 240 pikul gula). ${ }^{3}$ Hal ini menunjukan betapa cepatnya populasi pribumi akrab dengan uang yang kemudian tidak terlepas dengan sistem upah yang menggejala di setiap pekerjaan yang dilakukan.

Persoalan yang akan dibahas dalam sub-sub bab berikut berkaitan dengan sistem upah yang diberlakukan selama kurun cultuurstelsel. Sub-bab pertama merupakan penegasan bahwa sepanjang kurun ini upah memang diberikan, terutama dalam onderneming gula. Hal ini perlu dibicarakan karena adanya keraguan dari segelintir peneliti tentang pengoprasian upah. Pada dasarnya para peneliti tersebut beranggapan, kerja-kerja yang dilakukan adalah gratis, merupakan pajak kerja atas tanah yang dibagikan oleh gubernemen. Sub-bab kedua akan mengangkat

${ }^{3}$ Arsip Karesidenan Pekalongan 82/1 B, hal 165 
peristiwa protes dari para pengusaha perkebunan tebu (planter) terhadap upah yang terlampau kecil, dan juga melihat bagaimana gubernamen menganalisa dan menyelesaikan masalah tersebut. Sedang sub-bab terakhir membicarakan analisa penulis terhadap peristiwa tersebut. Dalam sub-bab ini akan diuraikan pengukuran besarnya tingkat upah dibandingkan dengan harga kebutuhan hidup sehari-hari

\section{A. Upah Kurun Cultuurstelsel}

Ada keraguan dari segelintir peneliti Jawa abad ke-19, khususnya tentang keberadaan upah yang diterapkan dalam onderneming pada umumnya. Keraguan ini berangkat dari dugaan:

"Pemerintah kolonial menentukan, bahwa pajak tanah harus dibayarkan dengan kerja bakti di perkebunan-perkebunan. Itu berarti, bahwa para petani tidak akan menerima upah untuk pekerjaan di perkebunan, karena kerja bakti yang dilakukan sebagai ganti pajak tanah. Dengan sendirinya pajak tanah tidak perlu dibayar lagi oleh petani yang memiliki tanah." 4

Landasan pijak pernyataan ini secara teoritis benar, karena asumsinya perekrutan tenaga kerja yang dilakukan oleh cultuurstelsel adalah kerja rodi di bawah pengayoman lembagalembaga heerendienst maupun cultuurdienst. Namun pada saat data ini dihadapkan dengan data primer, maka dugaan tersebut

4 Onghokham, Pulung Affair: Pemberontakan Pajak di Desa Patik Beberapa Aspek Politik Desa di Madiun Pada Abad ke-19 MISI Jilid VII, No. 1 (Jakarta, 1877) hal. 11. Hal serupa dinyatakan pula oleh Wertheim, dalam bukunya W.F. Wertheim, Indonesian Society in Transition: A Study of Social Change (Den Haag, 1959) yang mengatakan: "The work had to be performed without pay." (hal. 469). 
segera hapus dengan sendirinya, sebagai dapat dilihat dalam industri gula. Sebabnya dalam regulasi-regulasi di awal cultuurstelsel, seperti Resolutie der Hooge Regering 5 Desember 1832 no. 1, yang menjadi landasan tulisan Van den Bosch, ${ }^{5}$ terdapat penjelasan mengenai upah-upah yang dibayarkan kepada buruh onderneming gula. Seperti untuk cultuurdienst, upah-tanam (plantloon) diberikan dengan syarat, jika:

"Ingeval het suikerriet in massa meer mogt oplevaren dan 14 pikols per bouw, zal 1/3 dan van komen ten voordeele van gouvernement, 1/3 ten voordeele der chinesche mandoors, en $1 / 3$ ten voordeele van den planter." 6

Tentu timbul pertanyaan, mengapa upah tersebut harus dibayarkan hanya jika jumlah produksi tebu melebihi 14 pikul untuk tiap-tiap bau? Untuk menjawabnya perlu diajukan perhitungan-perhitungan yang dipakai gubernemen. Dalam pasalpasal suiker-contract yang diajukan pada kaum tani, biasanya dinyatakan bahwa tanah yang diberikan pada petani mempunyai nilai uang sebesar 20 hingga 30 rupiah (gulden). Selain itu petani yang bersedia bekerja pada gubernemen juga dibebaskan dari beban membayar uang kuli gladag satu gulden. Kemudian, Bosch menambah dengan besarnya pajak-tanah pada tanah yang dibagikan tersebut sebesar 7, 50 gulden. Jumlah keseluruhan uang tersebut diperhitungkan sebagai hutang yang harus dilunasi dengan serangkaian kerja menanam dan memelihara tebu yang untuk tiap bau kebun diperhitungkan menghasilkan sebanyak 14 pikul. Hal ini menjadi inti perhitungan pajak-kerja cultuurstelsel.

\footnotetext{
5 AKP/Bosch 1834

${ }^{6}$ Ibid., bijlage $B$.
} 
Melalui logika-logika yang diperhitungkan dengan angka-angka fiktif tersebut, gubernemen bisa menyerap kerja gratis atau kerja dengan upah sangat murah dari petani.

Untuk menggampangkan mekanisme kerja diatas maka organisasi pengarahan kerjanya dilakukan dengan menetapkan kerja wajib bagi desa. Namun dengan sistem pengerahan kerja secara sedesa-sedesa timbul masalah, yaitu beban kerja berbedabeda bagi masing-masing desa, sebagai dibicarakan oleh Burger:

"Desa-desa yang dikenaknan padjak tanah jang tinggi kadang-kadang melakukan pekerdjaan jang lebih sedikit daripada desa-desa jang padjak lebih rendah."7

Sehingga menjadikan regulasi yang dibuat Van den Bosch di atas sedikit dimodifikasi, yaitu dengan keputusan pemerintah kolonial yang intinya mengatakan:

“[...] pembebanan itu hampir dimana-mana diganti dengan pembajaran upah tanam setjara perseorangan kepada orang-orang jang berkewadjiban menanam, sehingga memungkinkan pembajaran menurut prestasinja [...]" 8

Selain cultuurdienst, kerja-kerja seperti penarik gerobak, pengumpul bambu, batu-bata, kapur dan kayu, dan kuli atau buruh dalam pabrik, ditetapkan upah tanpa beban kerja rodi atau

7 DH. Burger, Sedjarah Ekonomis Sosiologis Indonesia, hal. 188

8 Ibid., hal. 188 
gratis. ${ }^{9}$ Kerja diperhitungkan berdasarkan prestasi kerja, yaitu kemampuan setiap buruh dalam melakukan kerja menentukan besaran upah yang dibayarkan.

\section{Planter Menggugat Upah 10}

Dalam bulan Mei 1842 pada saat terjadi rotasi penanaman lahan tebu di kabupaten Batang, pada desa-desa Kaliepoetjang Koelon, Karanganjar dan Wates Ageng. Lahan-lahan tebu tersebut akan diperluas penanamannya dan membutuhkan penyerahan tanah-tanah baru. Residen meminta tanah-tanah yang kondisinya lebih baik untuk dipakai menanam tebu dalam jangka dua tahun. Intruksi gubernemen ini disampaikan langsung oleh bupati Batang kepada para kepala desa.

Namun pada 22 Oktober, kontrolir Batang melaporkan, sejumlah 46 desa yang penduduknya melakukan cultuurdienst tebu untuk masa tanam tahun yang lalu belum dilunasi upahnya untuk kerja musim panen tahun ini. Sebabnya, mereka dianggap belum cukup memenuhi pajak natura tebu yang harus diserahkan, yang ada dalam kontrak-kontrak tahun 1841 dengan upah sebesar 14,22 gulden per kepala.

Keadaan menggenting planter dan petani tebu yang terlibat onderneming tersebut tidak mau melunasi pajak natura yang dibebankan melainkan justru melakukan tuntutan untuk kenaikan upah dari 14,22 gulden menjadi 25 gulden.

9 Hingga tahun 1836 hanya pabrik gula saja yang mempunyai ordonansi perupahan tertulis ["Fabriekenordonnantie", ENI Jilid 1 (Leiden: Martinus Nijhoff, 1917), hal. 697]

10 Penjelasan berikut ini semata-mata didasarkan pada Besluit 2 Februarij 1843. Namun karena dalam menyusun besluit dilakukan diskusi-diskusi yang terdiri dari missive antar lembaga, maka guna menyingkat penulisan sumber primer, untuk seterusnya peristiwa di bawah tidak mencantumkan besluit sumber. 
Isu untuk menuntut kenaikan upah dengan sangat cepat menyebar ke desa-desa lain. Sehingga pada 24 Oktober terdapat 600 planter dari 51 desa $^{11}$ bergabung langsung menghadap ke rumah residen menuntut kenaikan upah.

Terdapat tiga hal yang digugat para planter, seperti dilaporkan Jaksa Besar, Prawiro Widjoijo, pertama, mereka menolak bagian tanah yang harus dikerjakan untuk ditanami tebu karena kondisi tanah tersebut buruk; kedua, menuntut kenaikan upah dari f 14,22 menjadi f 25; ketiga, planter menolak menanam paparan tebu karena pekerjaan untuk mengolah tanaman milik petani sendiri belum selesai, para planter bersedia menanam tebu kalau pekerjaannya telah selesai. ${ }^{12}$ Sebelum tuntutan dipenuhi oleh gubernemen, planter akan tetap menolak untuk bekerja, atau "mogok" (aanstaken).

Dalam konteks tuntutan di atas, gubernemen menyangkal tuntutan pertama para planter. Menurut penyelidikan yang segera dilakukan, terbukti bahwa laporan tersebut hanya mengada-ada saja, sekedar alasan untuk melakukan tuntutan pada gubernemen. ${ }^{13}$ Bagi gubernemen persoalan pertama di sini adalah tuntutan planter untuk kenaikan upah saja.

Pada dasarnya gubernemen setuju bahwa jumlah upah yang dibayarkan memang rendah, ${ }^{14}$ sebab para planter yang dipekerjakan tersebut umumnya tidak memiliki (menguasai)

11 Dalam tahun tersebut di kabupaten Batang terdapat 88 desa yang dilibatkan cultuurdienst tebu

12 Proces verbal 29 November 1842.

13 Missive Raad van Indie kepada Residen Pekalongan, 10 Desember 1842.

${ }^{14}$ Missive, Raad van Indie 10 Desember 1842; missive Residen Pekalongan kepada Directeur der Kultures, 4 Januari 1843 
tanah. ${ }^{15}$ Namun gubernemen pun tetap bersikeras bahwa planter telah melakukan persetujuan kontrak kerja dengan upah sebesar 14,22 gulden, dan janji tersebut harus tetap ditepati, tidak ada alasan untuk mengatakan tidak puas. ${ }^{16}$ Tuntutan planter tersebut merupakan tidakan: "kurang adjar," karena mengakibatkan terbengkalainya kebun-kebun tebu. ${ }^{17}$

Hanya dua missive yang menangkap dua persoalan secara agak jelas tentang penyebab peristiwa di atas, pertama dari Residen Pekalongan yang menjelaskan bahwa terjadi ketidak beresan dalam pembayaran upah di desa-desa, ${ }^{18}$ yang kemudian dianalisa oleh Directeur der Kultures. Adanya kesewenangwenangan yang terjadi dalam desa-desa oleh kepala desanya, terutama dalam melakukan penunjukan tanah yang dilakukan secara tidak adil, kemudian plantloon yang dibayarkan tidak merata karena diberikan melalui lurah, menjadikan banyak planter tidak menerima upah sebagaimana mestinya. Diluar pokok masalah ketidak beresan pembayaran upah dalam desa, Directeur der Kultures mengusulkan kepada Residen agar membayar penuh upah yang semestinya diberikan kepada planter sebesar 17,77 gulden, sesuai dengan proposal. ${ }^{19}$

15 Missive Residen Pekalongan kepada Directeur der Kultures 4 Januari 1843

16 Missive Raad van Indie 10 Desember 1842

17 Missive Residen Pekalongan 4 Januari 1843

18 Missive, 12 November 1842

19 Missive Directeur der Kultures kepada Residen Pekalongan, 13 Januari 1843 
Meskipun pada akhirnya segala usul berhenti sebagai usul saja, karena Direktur Algemeene Secretarie telah menolaknya20 sehingga tindakan yang dipilih adalah pemulihan kondisi rust en orde bagi para penanam tebu (atau gubernemen). Akan tetapi terlepas dari penilaian baik-buruk pembuangan ke-empat orang tersebut, yang jelas para planter kini kembali bekerja dan tidak melakukan tuntutan lagi. ${ }^{21}$ Paling tidak pembuangan tersebut menjadi tindakan tepat bagi gubernemen.

\section{Upah Riil}

Ada hal yang sebenarnya cukup penting dalam tuntutan planter di atas namun diabaikan dalam analisa gubernemen terhadap peristiwa planter menggugat. Karena, gubernemen hanya memusatkan persoalan pada satu dari tiga tuntutan planter, yaitu upah saja. Sedang penolakan planter untuk menanam lahan yang dianggap berkondisi buruk, dan menolak atau menunda menanam paparan tebu karena pekerjaan untuk mengolah tanaman milik petani sendiri belum selesai, diabaikan begitu saja. Selain itu meskipun dugaan gubernemen bahwa salah seorang dari penghasut gugatan upah diatas adalah orang berpengaruh di desa, atau lurah, namun analisa gubernemen hanya sampai pada menilai sikap sewenang-wenang dari elit desa tersebut terhadap rakyatnya; sedang alasan mengapa seorang kepala desa menghasut, yang menjadi pangkal dari planter menggugat, justru tidak terungkap.

Pribumi berpengaruh sebenarnya telah terlibat dalam produksi barang-dagangan, seperti para bupati, para kepala

20 Missive kepala Residen Pekalongan, 16 November 1842

21 Hal ini menjadi penegasan akhir dsari "diskusi" antar lembaga di atas dan disimpulkan dalam Besluit 2 Februari 1843. Ke empat penghasut kemudian di pindahkan dari penjara Semarang ke Krawang 
distrik, dan berlanjut pada lapisan orang yang ber hak istimewa dalam desa. Singkatnya telah muncul kesadaran entrepreneur di kalangan pribumi, yaitu tanah bisa dijadikan alat yang menghasilkan laba lebih besar bila diolah sendiri. Tentu timbul pertanyaan berapa selisih labanya jika sebidang tanah diolah sendiri dengan jika diolah bagi kepentingan gubernemen? Dari penghitungan yang dilakukan bupati Wirio Dhi Negoro, bila sebidang tanah ukuran satu bau ditanami padi atau ketela atau jagung setelah mengeluarkan ongkos-ongkos bibit dan upah bagi penerjaannya sekitar 1,44 gulden maka hasilnya bisa dijual sebesar 21 hingga 22 gulden. Jika tanah tersebut dipakai untuk menanam tebu bagi penggilingan-penggilingan Cina yang masih beroprasi akan mendapat 80 gulden. ${ }^{22}$ Dan paling tidak untuk tanaman bukan tebu, setahun bisa menanam tiga kali, jadi pendapatan bersih dari satu bau tanah adalah 61,68 gulden. Kalau tanah tersebut dipakai untuk tebu gubernemen, selama 2 tahun, hanya diberikan pengganti sebesar 56,88 gulden (upah bagi 4 orang pengolah yang masing-masing menerima 14,22 gulden), suatu jumlah pendapatan riil yang jauh berbeda.

Dari deskripsi ini menjadi cukup beralasan jika petani-kaya lebih memilih mengusahakan tanahnya sendiri untuk suatu produk pertanian daripada jika memberi waktu dan tenaganya untuk onderneming gubernemen. Sehingga cukup beralasan jika

22 Lihat laporan tahun 1835: "Njang terseboet die bawa snie menoendjoeken atoeran sawa, dieija orang poenja pakerdjaan bolenja tanem apa-apa, die dalem ietoengan njang satoe baoe." (AKP7/1). Hal serupa juga dilaporkan oleh Residen Praetorius dalam laporan perbandingan sebelum dan setelah diberlakukannya cultuurstelsel (AC 46). Beberapa tahun sebelumnya kaum "fabriekant" Cina malah menjanjikan jumlah uang lebih besar bagi para penanam tebu, untuk satu bau lahan tebu diberi ongkos pengganti sebesar f 125 (AKP 82/1 B). Hal inilah yang kiranya lebih mendorong kaum petani-kaya tidak atau segan membantu proyek penanaman tebu gubernemen. 
mereka mengorganisir planter lainnya dengan cara menghasut, untuk mengajukan tiga tuntutan seperti telah disebutkan di atas.

Persoalan utama yang melandasi analisa gubernemen adalah masalah upah. Namun tidak dijelaskan mengapa gubernemen tetap bertahan pada tingkat upah yang dianggap tidak memadai kalau pada dasarnya disadari bahwa upah tersebut terlalu rendah. Di lain sisi seolah-olah gubernemen cukup sadar untuk menerima kondisi bahwa upah mesti dibayarkan sesuai dengan kondisi biaya hidup setempat. Hal ini pernah diutarakan pada awal didirikannya pabrik-pabrik modern, antara tahun 18371838, Residen Pekalongan telah membuat surat edaran, yang secara singkat mengingatkan pada kaum fabriekant bahwa upah yang mesti dibayarkan dalam karesidenan ini lebih tinggi dari di tempat lain: "Dat de koelieloonen in deze Residentie hooger dan Djapara zijn."23 Namun dilain sisi Raad van Indie melihat pemberian upah kepada para planter telah memadai tanpa melihat kondisi riil, perbandingan antara upah dengan harga pasar:

"Di bawah komentar bahwa oleh rakyat (dianggap dari seluruh Jawa) untuk panen gula tahun 1840 maksimum $f$ 32.73, dan minimum $f 6.41$ per $k k$ [...] jadi $f 14.22$ adalah jumlah yang jauh dari rata-rata tahun 1840."24

Kalau demikian tentu timbul pertanyaan, bagaimana orangorang tersebut diatas memperhitungkan tinggi atau rendahnya jumlah upah yang mesti dibayarkan pada buruh-buruh pribumi?

23 Missive Residen Pekalongan kepada Directeur der Kultures 6 November 1837, AC 1624

24 Missive 10 Desember 1842 
Mengapa pendapat yang satu menjadi tidak konsisten bila dihadapkan dengan pendapat yang lain?

Secara teoritis upah ditentukan nominal, yaitu sejumlah uang tunai yang diterima oleh buruh. Namun perhitungan seperti ini seringkali mengabaikan kondisi riil harga-harga kebutuhan pokok sehari-hari, yang bisa didapat dari jumlah nominal yang diterima buruh tersebut. Jadi, upah seharusnya ditentukan secara riil, atau kondisi harga kebutuhan riil menentukan besarnya upah nominal. Bagi buruh, upah riil lebih besar artinya daripada upah nominal, sebab seandainya upah nominal naik, sedangkan pada saat yang sama harga-harga kebutuhan hidup naik dengan prosentase yang sama, maka upah riil akan tetap tidak berubah. ${ }^{25}$ Secara singkat masalah ini pernah ditanyakan dengan kata-kata sebagai berikut:

"Harga-tenaga kaoem boeroeh sama dengan keperloean penghidoepannja oentoek mengembalikan tenaga jang terpakai (reproductie kekoeatannja). Dan keperloean penghidoepan ini boekan sadja makanan peroet, akan tetapi joega makanan otak. Oleh karenanja maka harga tenaga itoe tidak tetap, akan tetapi toeroen-naik, berobah.”26

Pemerintah kolonial mestinya cukup sadar tentang sistem upah yang diterapkannya. Namun mencegah terjadinya pelonjakan yang akan mengacaukan harga produk dan juga laba yang dikedur dari Jawa, maka gubernemen menetapkan besar upah maksimal secara sepihak: hal 121

25 J. van Zwijndregt dan B.H. Schoonenberg, Peladjaran Ekonomi, ${ }^{26}$ Sjahrir, Pergerakan Pekerdja (Jakarta: Daulat Ra’jat) hal. 2 
"Pemerintah mendjaga agar upah-upah itu djangan meningkat. Pemerintah mempertimbangkan untuk mengatur upah-upah kerdja itu dengan kekuasaan tertinggi." 27

Namun yang terjadi di Karesidenan Pekalongan selama tahun-tahun awal beroperasinya onderneming-onderneming gula adalah kemrosotan produksi tanaman pokok yang mengakibatkan pelonjakan harga beras. Sehingga hal ini dapat menjadi salah satu penyebab yang memudahkan menyulut para planter gurem, tuantanah, untuk menuntut upah lebih besar.

Kelabilan atau (fluktuasi) pada harga kebutuhan pokok, memaksa gubernemen setiap tahun melakukan penetapan regulasi-regulasi baru untuk tingkat upah maksimal. Seperti selama tahun 1840-an upah bertahan antara 12 hingga 15 duit; dan sejak 1850 antara 15 sampai 20 duit, sedang untuk kuli yang bersedia kerja nonstop siang-malam sekaligus mendapat 40 duit. Tetapi untuk kerja-kerja pengawas atau mandor upah per hari jauh lebih besar sekitar 40 duit. ${ }^{28}$ Apa yang diregulasikan tidak harus sesuai dengan apa yang dipraktekan, seperti dalam pertengahan abad ke tiga, pabrik di Pekalongan membayar upah untuk kerja siang hari antara 15 (Sragie) hingga 18 duit (Kalimatie dan Wonopringo); dan untuk kerja malam hari antara 18-20 duit. ${ }^{29}$ Jelas meski jumlah selisih upah antara regulasi dengan yang diberikan pabrik sangat kecil, antara 2-5 duit, namun jumlah

27 D.H. Burger, Sedjarah Ekonomis Sosiologis Indonesia, hal 188.

28 Lijst van Ingekochte Materialen en Verwerkte Arbeidsloonen 1842-1859, AKP 20/1; Kultuur Verslag 1962 sub “Dagloonen”, AC 1624

${ }^{29}$ AC 1624 
upah seperti ini ternyata tidak pernah memunculkan gugatan baru, selain peristiwa di atas hingga berakhirnya cultuurstelsel. Padahal sejak 1850 untuk plantloon terjadi penurunan dari 14,22 gulden di tahun 1840-an, menjadi sedikit lebih dari 13 gulden. ${ }^{30}$

Jadi agaknya, memang erat kaitan antara upah dengan harga kebutuhan sehari-hari. Sehingga dinyatakan oleh Residen dalam tahun 1852:

"Bahan makanan pada umumnya murah dan kita dapat hidup mudah dengan 10 a 12 duit per hari." 31

Karena harga kebutuhan pokok minimal kini bisa ditekan tanpa mengalami kelabilan (fluktuasi) yang berdampak terhadap besarnya upah. Hal ini menunjukan bahwa gubernemen pun cukup sadar atas kondisi riil para buruhnya. Sehingga ketika Commissie Umbgrove, yang kemudian harus merancangkan perbaikan-perbaikan dalam cultuurstelsel menasehatkan untuk mempertahankan pembayaran upah-upah itu, ${ }^{32}$ hal tersebut dapat terlaksana. Umbgrove sendiri melihat kenyataan yang ditemui selama penelitian komisi tersebut, bahwa terdapat buruh-buruh tak bertanah mengakibatkan mereka harus memperoleh

30 Verslag betreffende de suiker cultures, met aantoning der uitkomsten 1861, RA 120

31 AC 1624

32 AC 1584. Selama penelitiannya di Pekalongan, commissie umbgrove mencatat upah-upah yang diberikan pabrik-pabrik gula tersebut sebagai berikut: upah penarik gerobak 15 duit; kuli pabrik untuk kerja satu shift (siang atau malam saja) sebulan f 5,40; pengumpul bambu 10 duit per gerobak; untuk pengangkut batu-bata 45 duit per 1.000 biji (harga batu-bata tersebut $\mathrm{f} 3,50$ ); dan untuk mengangkut kapur 32 duit per koyang. 
kebutuhan pokok sehari-hari dengan membeli. Sehingga upah menjadi sangat diperlukan.

\section{Kesimpulan}

Bagi masyarakat pribumi Jawa hadirnya kolonialisme beserta lembaga-lembaga bentukannya sangat besar pengaruhnya, terutama di sekitar hadirnya industri agrikultur dan sistem upah yang berwujud pabrik gula. Korban-korban cultuurstelsel dalam bentuk masyarakat Jawa umumnya dan khususnya di Karesidenan Pekalongan, pertama sistem ini telah berhasil ditegakan dengan menghancurkan lapisan elit setempat sebagai pengusaha pribumi (domestik) yang mulai tumbuh, -yang menjadi lawan-lawan efektif bagi industri agrikultur gubernemensekarang tidak lebih hanya menjadi pejabat bergaji dalam barisan Pangreh-Praja. Kedua, industri gula yang menyerap tanah, air, dan tenaga kerja secara besar-besaran telah membawa dampak hancurnya kebutuhan pokok petani, beras. Hal ini mendorong dampak ketiga, yaitu terjadi proletarisasi yang secara riil terwujud dengan munculnya kuli dan atau wong boeroeh. Suatu kelas buruh yang timbul sebagai jawaban atas kepadatan penduduk yang mulai tidak bisa diatasi oleh sistem perekonomian pedesaan Jawa lama. Tegasnya terjadi transformasi pada masyarakat pribumi, yakni penglepasan petani dari hak mengolah tanah desa dan kini menjadi penjual tenaga kerja. Dengan munculnya buruh Jawa, maka pengerahan tenaga dalam bentuk kerja kontrak (suiker-contract) menjadi tidak diperlukan lagi. 33

${ }^{33} \mathrm{Hal}$ ini menjadi antiklise dari perkembangan yang berlangsung di Sumatera. Kalau pola pengerahan tenaga kerja di Sumatera landasan utamanya adalah kerja kontrak, atau kuli kontrak, yang didatangkan dari Jawa. Sedang perkembangan di Jawa justru kebalikan dari di Sumatera, yaitu kerja kontrak tergeser dengan melimpahnya buruh pribumi. 


\section{Referensi}

$\mathrm{AC} 1584$

: Angket melalui tanah, desa, penduduk, jalan dan lain-lain, yang dijawab oleh lingkungan, pengusaha perkebunan Karesidenan Pekalongan, dengan daftar-daftar kira-kira 1854. [Commissie Umbgrove].

$\mathrm{AC} 1624$

: Laporan Tahunan Karesidenan Pekalongan 1834-1865.

AKP7/1-4 : : Inkomende Uitgande Regten.

AKP20/1 : Lijst van Ingekochte Materialen en Verwerkte Arbeidsloonen 1842-1859.

AKP73/1 Nb. 39 : Suiker Contracten tussen de Gouverment en resident Pekalongan en de dessa's hoofden, 1830-1833.

AKP82/1 B : Statistiek van de Residentie Pekalongan 1820.

AKP/Bosch 1834 : Eenige Zakelijke Extracten uit een Algemeen overzigt, door Z.E. den Komissaris Generaal Van den Bosch, te zamen gesteld, gedagteekend 24 Januarij 1834. Disisipkan dalam AKP 7/1-4.

RA120

: Verslag betreffende de suiker cultures, met aantoning der uit komsten 1861.

Burger, DH, Sedjarah Ekonomi Sosiologis Indonesia. Jilid I, (Cetakan ke-3). Jakarta: Pradnjaparamita, 1962.

Ikhtisar Keadaan Politiek Hindia-Belanda Tahun 1839-1848. Arsip Nasional Rebublik Indonesia No. 5, Jakarta, 1973.

Knight, Gordon R, From Plantation to Padi-field: The Origin of the Nineteenh Century Transformation of Java's Sugar Industry. Modern Asia Studies, 1980. 
Onghokam, Pulung Affair: Pemberontakan Pajak di Desa Patik beberapa Aspek Politik Desa di Madiun Pada Abad ke19. MISI Jilid VII, No. I, 1877.

Paulus, J (red.), Fabriekenordonnantie, ENI. Jilid I. Leiden: Martinus Nijhoff, 1917.

Sjahrir, Pergerakan Sekerdja. Jakarta: Daulat Ra’jat, 1933.

Suri Suroto, Gerakan Buruh dan Permasalahannya Prisma, No. 11 Jakarta: LP3ES, 1985.

Wertheim, W.F, Indonesian Society in Transsition: A Study of Social Change. Cetakan ke-2. Den Haag, 1959

Zwijndregt, J. van dan Schoonenberg, B.H, Peladjaran Ekonomi. Disadur oleh Hasan Amin, cetakan ke-3. Jakarta: J.B. Wolters, 1954. 